\section{LEY DE PROMOCIÓN DE ALIMENTACIÓN SALUDABLE: ¿JUGANDO A LA POLÍTICA CON LA SALUD DE LOS NIÑOS?}

\author{
LAW OF HEALTHY EATING PROMOTION: \\ PLAYING POLITICS WITH THE HEALTH \\ OF CHILDREN?
}

\section{Daniel Antiporta ${ }^{1, a}$, J. Jaime Miranda ${ }^{1, b}$}

Sr. Editor. La reciente publicación de los parámetros referentes al contenido de azúcar, sodio y grasas saturadas correspondientes a la Ley 30021 de Promoción de la Alimentación Saludable ${ }^{(1)}$, tras dos años de aprobarse, merece, desde nuestro punto de vista, algunas precisiones y reflexiones de los fundamentos, del por qué de la ley, así como de los argumentos comúnmente expuestos en su contra.

Durante el 2012, las enfermedades crónicas no transmisibles (ECNT) han sido responsables de más de 3,5 millones de años de vida saludables perdidos (AVISA), ubicándose como la principal causa de carga de enfermedad en nuestro país. Además, el exceso de peso constituye un serio problema de salud pública que afecta a todos los grupos etarios, sin mencionar que está en constante aumento. Esta situación se agrava con el aumento de ventas de productos ultraprocesados como las comidas rápidas, snacks densamente energéticos y bebidas azucaradas; relacionados con un mayor índice de masa corporal, diabetes y algunos tipos de cáncer ${ }^{(2)}$.

Por otro lado, el marketing es usado para llegar a los niños, con la finalidad de aumentar el reconocimiento y fidelización a sus marcas, e incrementar sus ventas ${ }^{(3)}$. Las Observaciones Generales 15 y 16 del Comité de Derechos del Niño, se refieren con preocupación a la publicidad de productos con grasas trans y alto contenido en azúcar, sal y aditivos, debido a su posible impacto nocivo en la salud de los niños. Además, tanto la Organización Mundial de la Salud (OMS) como el Instituto de Medicina de los Estados Unidos afirman que la publicidad televisiva influye en las preferencias alimentarias y de consumo en los niños.

No obstante, la abrumadora evidencia científica, la respuesta del sector industrial y de algunos grupos del

\footnotetext{
CRONICAS Centro de Excelencia en Enfermedades Crónicas, Universidad Peruana Cayetano Heredia, Lima, Perú.

a Licenciado en nutrición; ${ }^{b}$ Médico, magíster y doctor en Epidemiología Recibido: 20-05-15 Aprobado: 03-06-15
}

Citar como: Antiporta D, Miranda JJ. Ley de promoción de alimentación saludable: ¿Jugando a la política con la salud de los niños? [carta]. Rev Peru Med Exp Salud Publica. 2015;32(3):603.
Parlamento han sido contrarias a la Ley, de tal modo que se ha llegado a plantear una propuesta de modificación (4). Dicho documento pone en duda los parámetros aprobados por la OPS/OMS sobre alimentos no saludables, los cuales han sido reafirmados en diversas ocasiones por dicha organización; y que, enhorabuena, han sido tomados en cuenta en el reglamento aprobado por el MINSA. Se intenta, también, crear un ambiente "antiindustria" afirmando que la ley prohíbe la venta de todos los productos procesados; falacia desmesurada ya que la ley regula la venta, -en quioscos escolares- solo de aquellos productos que sobrepasen los parámetros establecidos en el reglamento. Otra particular sugerencia es la inclusión de la "industria" en el Observatorio de Nutrición y de Estudio del Sobrepeso y Obesidad, omitiendo que dicha acción crearía conflictos de interés por ser, precisamente, las empresas de productos comestibles las que están siendo reguladas.

Finalmente, las recomendaciones de la OMS de eliminar las grasas trans de origen industrial, debido a sus efectos nocivos relacionados con la incidencia de ECNT ${ }^{(5)}$, han sido omitidas en este reglamento.

Si bien los parámetros han sido aprobados, la implementación de estos parece aun lejana pues depende de la elaboración y aprobación del reglamento de la Ley a cargo de una comisión intersectorial. Mientras tanto, ¿seguiremos -como dice Michelle Obama- jugando a la política con la salud de nuestros niños?

\section{REFERENCIAS BIBLIOGRÁFICAS}

1. Perú, Ministerio de Salud. Decreto Supremo 007-2015-SA. Reglamento que establece los parámetros técnicos sobre los alimentos y bebidas no alcohólicas procesados referentes al contenido de azúcar, sodio y grasas saturadas. Lima: MINSA; 2015.

2. Pan American Health Organization, World Health Organization. Consumption of ultra-processed food and drink products in Latin America: Trends, impact on obesity, and policy implications. Washington, DC: PAHO; 2014.

3. Story M, French S. Food Advertising and Marketing Directed at Children and Adolescents in the US. Int J Behav Nutr Phys Act. 2004;1(1):3.

4. Perú, Congreso de la República. Proyecto de Ley 4343/2014CR que modifica diversos artículos de la ley No 30021, ley de promoción de la alimentación saludable para niños, niñas y adolescentes. Lima: Congreso de la República; 2015.

5. Uauy R, Aro A, Clarke R, Ghafoorunissa, L'Abbe MR, Mozaffarian D, et al. WHO Scientific Update on trans fatty acids: summary and conclusions. Eur J Clin Nutr. 2009;63(S2):S68-75.

Correspondencia: Daniel Antiporta Peñaloza

Dirección: Centro de Excelencia en Enfermedades Crónicas.

Universidad Peruana Cayetano Heredia. Av. Armendáriz 497,

Miraflores, Lima 18, Perú

Teléfono: (+511) 987759432

Correo electrónico: daniel.antiporta.p@upch.pe 